\title{
Erratum to: Food and feed supply and waste disposal in the industrialising city of Vienna (1830-1913): a special focus on urban nitrogen flows
}

\author{
Sylvia Gierlinger ${ }^{1}$
}

Published online: 12 March 2016

(c) Springer-Verlag Berlin Heidelberg 2016

\section{Erratum to: Reg Environ Change (2015) 15:317-327}

DOI 10.1007/s10113-014-0653-5

The author would like to correct the following errors in the original publication of the article:

In Table 1, the value for eggs is given in number of eggs per capita and year and not $\mathrm{kg} / \mathrm{cap} / \mathrm{yr}$. The value for $\mathrm{kg} / \mathrm{cap} /$ yr would be 8 for the year 1830 and 4.4 for the year 1870 .

The online version of the original article can be found under doi:10.1007/s10113-014-0653-5.

Sylvia Gierlinger

Sylvia.gierlinger@aau.at

1 Faculty for Interdisciplinary Studies (IFF), Institute of Social

Ecology Vienna, Alpen-Adria University Klagenfurt,

Schottenfeldgasse 29, 1070 Vienna, Austria 